\title{
Enraizamento de estacas de Camellia sinensis L. em função da época de coleta de ramos, genótipos e ácido indolbutírico
}

\author{
Rooting of Camellia sinensis $\mathbf{L}$. in function of cutting collection time, genotypes and \\ indolebutyric acid
}

\author{
Juliana Domingues Lima ${ }^{*}$ Ana Paula de Souza Lima ${ }^{\mathrm{I}}$ Ana Carolina Batista Bolfarini ${ }^{\mathrm{I}}$ \\ Silvia Helena Modenese-Gorla da Silva ${ }^{\mathrm{I}}$
}

RESUMO

Objetivou-se avaliar o efeito da época de coleta de ramos, genótipo e concentração de ácido indolbutírico (AIB) no enraizamento de estacas de Camellia sinensis L. Para tal, foram coletados ramos dos genótipos IAC 259, F 15 e Comum, em Pariquera-Açu, SP, Brasil, no inverno, primavera, verão e outono. Em seguida, foram preparadas estacas que foram tratadas com AIB $(0,2.000,4.000,6.000$ e $8.000 e$ $10.000 \mathrm{mg}^{-1}$ ), plantadas em vermiculita e mantidas em viveiro sob $70 \%$ de sombreamento e irrigação periódica. O delineamento experimental foi o inteiramente casualizado, em esquema fatorial $4 \times 3 \times 6$ (quatro épocas, três genótipos e seis concentrações de AIB), com quatro repetições de oito estacas. A época ideal para se coletar os ramos foi o inverno. Estacas coletadas no inverno apresentaram mortalidade média de $41 \%$, enquanto nas estacas vivas o enraizamento médio foi de $66 \%$, influenciado apenas pelo genótipo, todas apresentaram brotações e apenas $32 \%$ apresentaram calos. O AIB influenciou o número e o comprimento das raízes formadas em estacas no inverno. Na primavera, apesar da menor mortalidade (31\%), apenas $0,34 \%$ das estacas vivas apresentaram raiz e 49\% brotação, enquanto $97 \%$ das estacas apresentaram calo. No verão e outono a mortalidade das estacas foi extremamente alta, respectivamente, 93 e $81 \%$ das estacas.

Palavras-chave: chá, propagação vegetativa, AIB.

\section{ABSTRACT}

The experiment was ${ }^{2}$ carried out to evaluate the effect of cutting collection time, genotype and indolebutyric acid (IBA) on rooting of Camellia sinensis L. cuttings. For such, stems were collected from three genotypes, IAC 259, F 15 and Comum, plants grown in Pariquera-Açu, São Paulo, Brazil, in winter, spring, summer and autumn. Cuttings were prepared and treated with IBA $(0,2.000,4.000,6.000$ and $8.000 e$ $\left.10.000 \mathrm{mg} \mathrm{L}^{-1}\right)$, planted in vermiculite and kept in greenhouse under $70 \%$ shading and periodic irrigation. The experimental design was completely randomized in a factorial scheme $4 \times 3 \times 6$ (four times, three genotypes and six concentrations of IBA) with four replicates of eight cuttings. The ideal time to cutting collection was in the winter. Cuttings collected in winter showed average mortality of $41 \%$. In the live cuttings the rooting medium was of $66 \%$, influenced only by the genotype. All had shoots and only $32 \%$ had callus. The IBA influenced the number and length of roots in cuttings in winter. In the spring, despite the lower mortality (31\%), only $0.34 \%$ and $49 \%$ of the live cuttings showed root and shoot respectively, while $97 \%$ of the cuttings showed callus. In summer and autumn mortality was extremely high representing 93 and $81 \%$ of the cuttings, respectively.

Key words: tea, vegetative propagation, IBA.

\section{INTRODUÇÃO}

Os chás produzidos a partir da infusão de folhas de Camellia sinensis L. movimentam bilhões de dólares todos os anos por possuírem propriedades medicinais bastante conhecidas e serem considerados alimentos funcionais (KHAN \& MUKHTAR, 2007; LIMA et al., 2009). No Brasil, a principal região produtora é o Vale do Ribeira, no Estado de São Paulo, onde a propagação de Camellia sinensis é realizada por meio da estaquia, utilizando material semi-lenhoso com única folha. O enraizamento das estacas é baixo pelo fato de essa espécie apresentar difícil enraizamento (SHARMA et al., 1999).

'Campus Experimental de Registro, Universidade Estadual Paulista “Júlio de Mesquita Filho” (UNESP), 11900-000, Registro, SP, Brasil. E-amil: judlima@ @egistro.unesp.br. *Autor para correspondência. 
Em espécies de difícil enraizamento, a dificuldade na formação de raízes nas estacas pode envolver a participação de fatores relacionados à própria planta e fatores relacionados ao ambiente, constituindo um sério problema, tornando importante a busca de técnicas auxiliares, como o uso de fitorreguladores.

Recomenda-se complementação com uma auxina sintética como o ácido indolbutírico (AIB) (BASTOS et al., 2009; OHLAND et al., 2009), que, no caso de Camellia sinensis, é imprescindível (ROUT, 2006), visto que o enraizamento na ausência de fitorreguladores é muito difícil. Em comparação com outras espécies lenhosas, Camellia sinensis requer altas concentrações de AIB (SHARMA et al., 1999), que variam de 3.000 a $8.000 \mathrm{mg} \mathrm{L}^{-1}$ (SENEVIRATNE et al., 1988; BANERJEE \& AGARWAL 1990; JHA \& SEN, 1992; ZEE et al., 2003). Diante do exposto, objetivou-se avaliar o efeito do genótipo, época e concentração de AIB no enraizamento de estacas semilenhosas de Camellia sinensis.

\section{MATERIAL E MÉTODOS}

Foram coletados ramos semilenhosos de três genótipos de Camellia sinensis L. cultivados no Vale do Ribeira, IAC 259, F 15 e Comum, na Empresa Yamatea, Pariquera-Açu, SP, no inverno (28/08/2009), primavera (23/09/2009), verão (23/12/2009) e outono (13/05/10). Em seguida, o material vegetal foi transportado para o Campus Experimental de Registro e preparadas estacas subapicais de cerca de $0,5 \mathrm{~cm}$ de diâmetro, com uma folha e duas gemas. Em seguida, feita a imersão da base da estaca em solução de ácido indolbutírico (AIB) 0, 2.000, 4.000, 6.000, 8.000 e 10.000 $\mathrm{mg} \mathrm{L}^{-1}$. Após o tratamento, as estacas foram colocadas em tubetes de $90 \mathrm{~cm}^{3}$, contendo vermiculita como substrato e mantidas em viveiro sob $70 \%$ de sombreamento e irrigação periódica. $\mathrm{O}$ delineamento experimental utilizado foi o inteiramente casualizado, em esquema fatorial $4 \times 3 \times 6$ (quatro épocas de coleta de ramos, três genótipos e seis concentrações de AIB), com quatro repetições de oito estacas.

As avaliações foram realizadas 60 dias após a instalação dos experimentos. As variáveis determinadas foram porcentagem de estacas vivas, mortas, enraizadas e com calo. Nas estacas enraizadas, foram determinados o número e o tamanho das raízes formadas.

A análise estatística foi realizada no programa estatístico Sisvar. Quando necessário, os dados foram transformados e submetidos à análise da variância por meio do teste $\mathrm{F}$, seguida da comparação das médias pelo teste Tukey ou análise da regressão. Além disso, para algumas variáveis foram feitas correlações pelo método de Pearson.

\section{RESULTADOS E DISCUSSÃO}

A época de coleta de ramos afetou a mortalidade e o enraizamento das estacas. A mortalidade no inverno foi de $41 \%$, não influenciada pelo genótipo, concentração e interação genótipo e concentração de AIB. Considerando apenas as estacas vivas, não houve efeito da concentração de $\mathrm{AIB}$ e da interação genótipo e concentração na porcentagem de enraizamento, no entanto, houve efeito do genótipo (Figura 1). Não houve diferenças na porcentagem de enraizamento das estacas do genótipo Comum quando comparado com F 15, e do genótipo F 15 em relação ao IAC 259. O enraizamento foi mais elevado no genótipo Comum quando comparado com o IAC 259. Todas as estacas vivas apresentaram brotações e apenas 32,49\% calos, as duas variáveis independentes do genótipo e concentração de AIB e interação entre esses fatores.

O número e o tamanho médio das raízes formadas em estacas coletadas no inverno foram influenciados significativamente pelo genótipo e pela concentração de AIB aplicada e pela interação entre esses dois fatores. Para o número médio de raízes formadas por estaca em função das concentrações de AIB nos três genótipos, o modelo de regressão de melhor ajuste foi o linear, indicando incremento no número de raízes com o aumento da concentração de AIB (Figura 2A). No genótipo F15, nas concentrações mais baixas do regulador de crescimento $(0,2.000 \mathrm{e}$ $\left.4.000 \mathrm{mg} \mathrm{L}^{-1}\right)$, o número de raízes formadas foi mais elevado quando comparado com os demais genótipos, porém, a $10.000 \mathrm{mg} \mathrm{L}^{-1} \mathrm{de}$ AIB, não houve diferença entre os genótipos. Para a variável comprimento médio das raízes formadas no inverno, no genótipo $F 15$, foi possível o ajuste do modelo de regressão linear e, para IC 259, o quadrático (Figura 2B). No entanto, para o genótipo Comum não foi possível ajuste de modelo de regressão, devido às variações no tamanho das raízes em função das concentrações de AIB terem sido reduzidas. A correlação entre a porcentagem de estacas com calo e estacas com raiz no inverno, independente da concentração de AIB e do genótipo, foi negativa, indicando que a presença de calo teve efeito negativo no enraizamento (Figura 3).

$\mathrm{Na}$ primavera, a mortalidade média das estacas foi $30,72 \%$, um pouco inferior ao observado no inverno $(40,76 \%)$, e sofreu apenas a influência do genótipo, sendo mais baixas as estacas do IAC 259 $(15,95 \%)$, quando comparadas com estacas do 


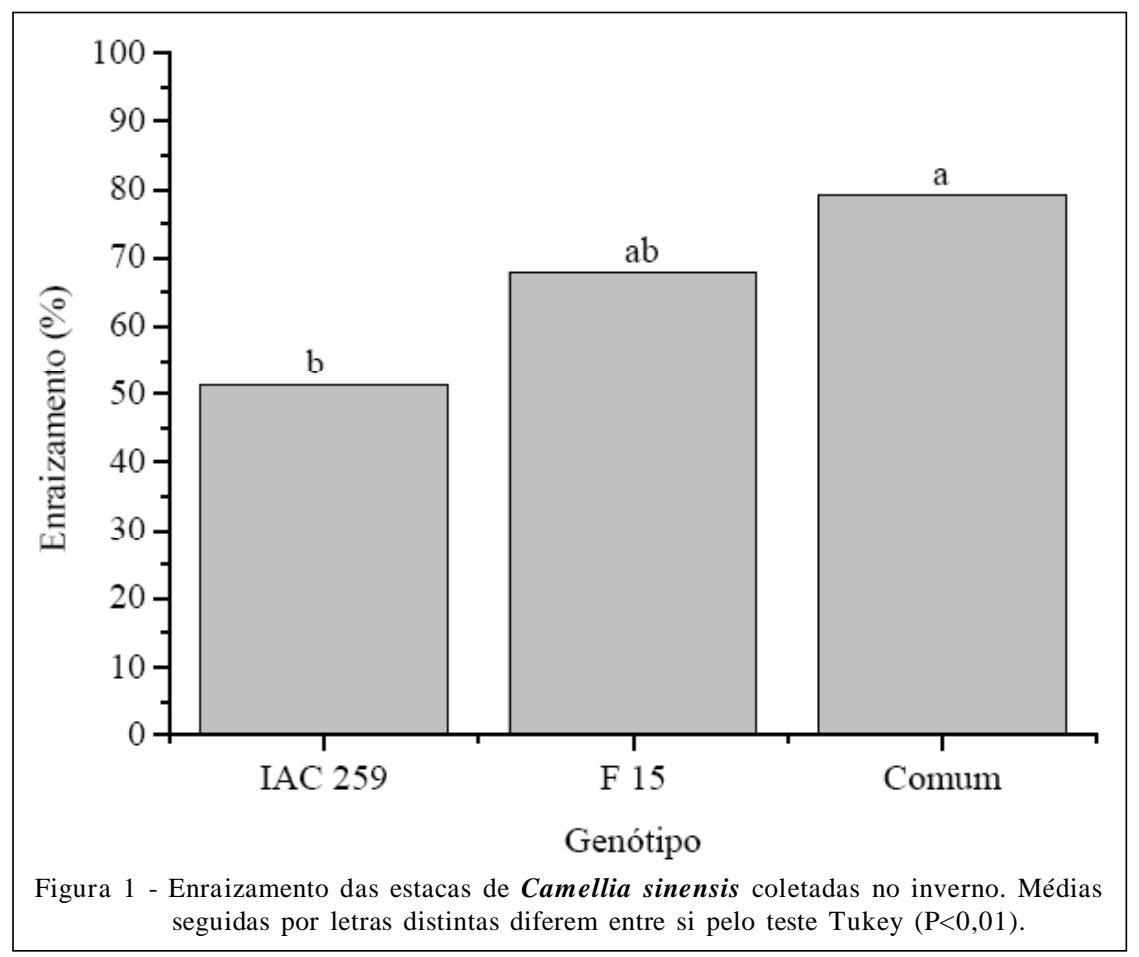

genótipo Comum (40,17\%) e, noF 15 (39,48\%), que não diferiram entre si. Todas as estacas vivas apresentaram brotações não influenciadas pelo genótipo e concentração de AIB utilizada. Cerca de 32,49\% das estacas apresentaram calo, cuja formação não foi influenciada pelo genótipo e concentração de AIB e nem pela interação desses dois fatores. A formação de raízes na primavera ocorreu apenas em $0,34 \%$ das estacas. No entanto, a formação de calos foi extremamente alta, pois para IAC 259 e Comum ocorreu em todas as estacas vivas. No genótipo F15, com exceção da concentração mais alta de AIB $\left(10.000 \mathrm{mg} \mathrm{L}^{-1}\right)$, cuja formação de calo ocorreu em $38 \%$ das estacas vivas, nas demais concentrações em $100 \%$ das estacas. Cerca de $86 \%$ das estacas apresentavam brotações, valor mais baixo do que no inverno e que também não foi influenciado pelos fatores isolados (genótipo e concentração de AIB) e nem pela interação entre eles.

No verão, a mortalidade média das estacas foi $92 \%$ e nenhuma das estacas vivas apresentou raiz. No outono, a mortalidade média das estacas foi de $81 \%$, apenas $0,69 \%$ das estacas vivas enraizaram e $2,78 \%$ apresentaram apenas calo.

O inverno foi a época em que se obteve o maior enraizamento médio (66\%), que foi influenciado apenas pelo genótipo. Esse valor está dentro do esperado para Camellia sinensis, que, segundo ZEE et al. (2003), varia de 40 a $80 \%$. Em todas as épocas de coleta a porcentagem de estacas mortas foi alta variando de cerca $30 \%$ a $92 \%$. Na primavera, apesar da maior sobrevivência das estacas, a porcentagem de enraizamento foi baixa, indicando que houve algum fator que impediu a formação das raízes, mas não a formação do calo e brotações.

Em espécies consideradas de difícil enraizamento, que demoram mais de 30 dias para enraizar (SARANGA \& CAMARON, 2007), como o Camellia sinensis, para o qual, neste estudo, o início da formação das raízes ocorreu em 45 dias, o maior tempo requerido para o enraizamento pode expor a estaca a condições ambientais subótimas (AIELLO \& GRAVES, 1998). Como consequência e frequentemente, a morte da estaca em espécies de difícil enraizamento está associada à desidratação do tecido (GRANGE \& LOACH, 1983) e uma possível limitação na resposta a auxinas exógenas (AMINAH, 2003). Neste estudo, a morte das estacas provavelmente foi causada pela desidratação.

A porcentagem de estacas com brotações foi alta no inverno e primavera. No inverno, também houve formação de raízes adventícias, indicando que o desenvolvimento das gemas axilares não inibiu o enraizamento, como em Backhousia citriodora, também considerada espécie de difícil enraizamento, já que o crescimento ativo das gemas axilares retardou ou inibiu a formação de raízes adventícias (KIBBLER et al., 2004). 


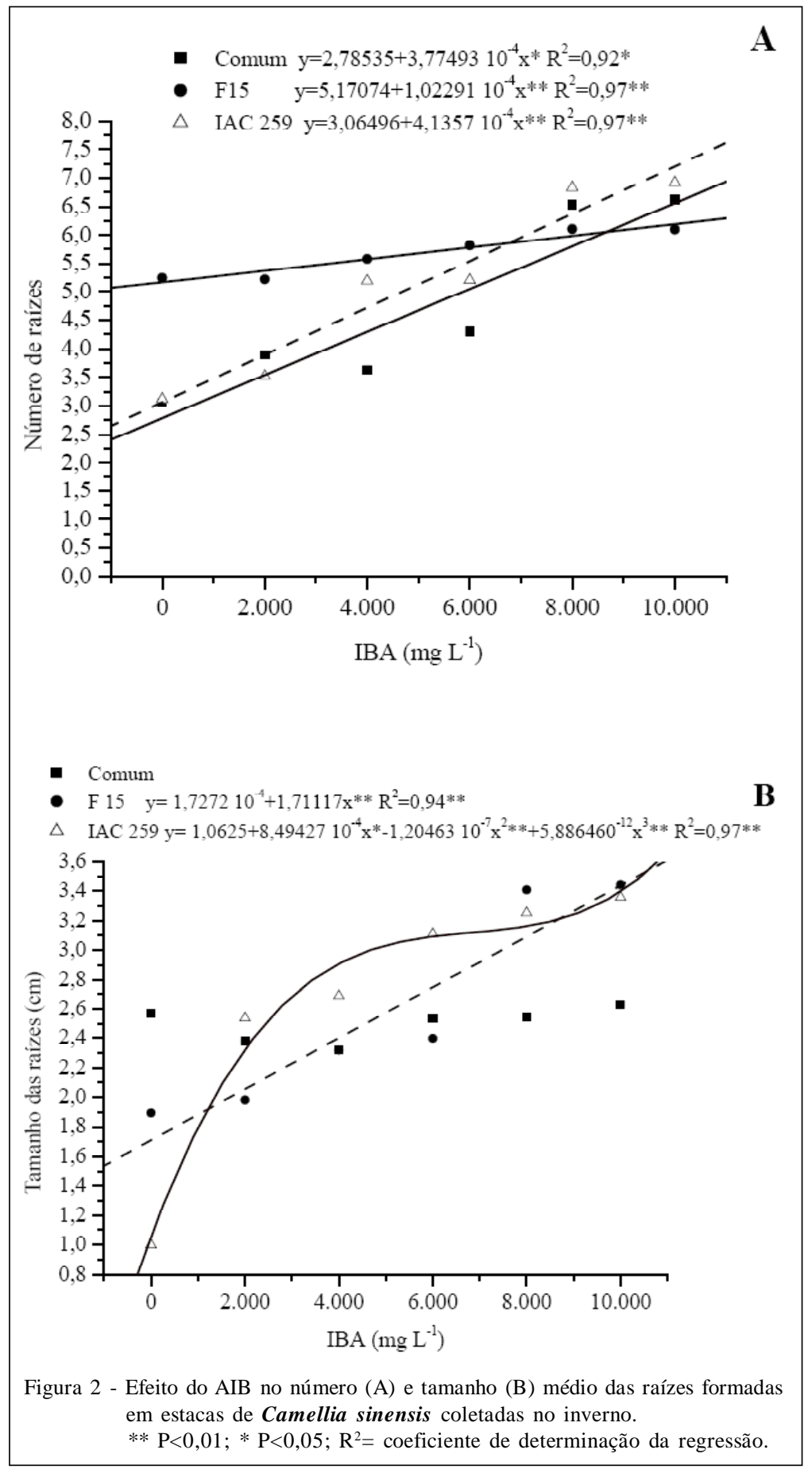

A maior formação de raízes nas estacas no inverno pode estar relacionada às condições ambientais do viveiro onde as estacas foram mantidas. Resultado que contraria o estudo realizado por YONGHONG et al. (2005) com Camellia sinensis, segundo o qual a alta razão AIA/ABA nas estacas se correlaciona positivamente com a taxa de enraizamento. Isso porque no inverno supõe-se existir maior nível de ABA na planta em relação ao nível de AIA. No campo, observase menor crescimento das plantas de Camellia sinensis nesta época, o que pode indicar a dormência. Como consequência, também era esperado maior efeito do AIB no enraizamento das estacas. No entanto, no inverno, a aplicação do AIB foi benéfica apenas para 


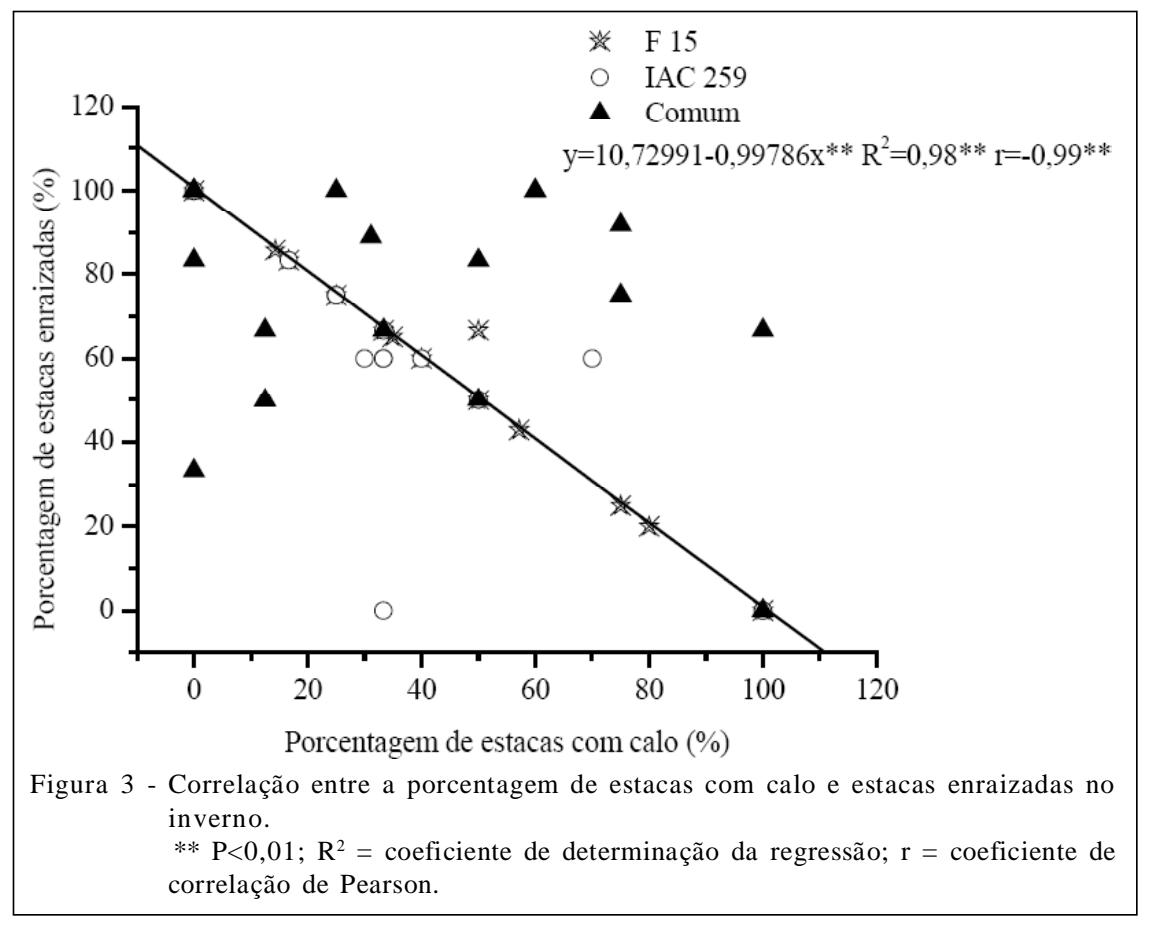

melhoria da qualidade das raízes formadas. Devido à resposta do número médio de raízes emitidas por estaca em todos os genótipos terem sido lineares, pressupõese que concentrações mais altas de AIB venham a promover resultados superiores. Respostas diferenciadas entre cultivares de Camellia sinensis quanto à capacidade de formação de raízes adventícias em estacas foram também observadas por ZHONGXU et al. (2001).

A formação de calo foi mais baixa no inverno e mais alta na primavera, demonstrando haver possivelmente uma relação inversa entre formação de calo e enraizamento, o que concorda com o estudo histológico realizado em clones de Camellia sinensis por YUERONG et al. (1985), no qual foi observado que a formação de raízes adventícias em estacas do caule foi precedida pela fase de desdiferenciação, ou seja, da formação de calo.

A presença da folha foi importante para manutenção da vitalidade da estaca, demonstrada pela correlação positiva, significativa, entre a porcentagem de estacas vivas e a de estacas com folhas, cujo coeficiente de Pearson (r) foi igual a 0,97 , independente da época, genótipo e concentração de AIB. A retenção foliar também foi importante para o enraizamento, sendo que todas as estacas enraizadas apresentaram folhas, independente da época, genótipo e concentração de AIB. O papel da folha no enraizamento de estacas semilenhosas está relacionado à fotossíntese, fornecimento de carboidratos (ALTMAN \& WAREING, 1975) e fornecimento de auxinas e co-fatores de enraizamento, transportados para a base das estacas (DAVIS, 1988).

\section{CONCLUSÃO}

Em viveiro, sob $70 \%$ de sombreamento, o enraizamento de estacas de Camellia sinensis é influenciado pela época de coleta de ramos, genótipo e concentração de AIB.

\section{AGRADECIMENTOS}

À Empresa Yamatea, pelo fornecimento de material vegetal e à FUNDUNESP e FAPESP, pela concessão de auxílio financeiro e bolsa.

\section{REFERÊNCIAS}

AIELLO, A.S., GRAVES, W.R. Success varies when using subirrigation instead of mist to root softwood cuttings of woody taxa. Journal of Environmental Horticulture, v.16, n.1, p.42-47, 1998. Disponível em: <http://www.hriresearch.org/ docs/publications/JEH/JEH_1998/JEH_1998_16_1/ JEH\%2016-1-42-47.pdf>. Acesso em: 25 mar. 2010.

ALTMAN, A.; WAREING, P.F. The effect of IAA on sugar accumulation and basipetal transport of ${ }^{14} \mathrm{C}$-labelled Phaseolus vulgaris cuttings. Physiologia Plantarum, v.33, n.1, p.3238, 1975. Disponível em: <http://onlinelibrary.wiley.com/doi/ 10.1111/j.1399-3054.1975.tb03760.x/pdf>. Acesso em: 25 mar. 2010. doi: 10.1111/j.1399-3054.1975.tb03760.x. 
AMINAH, H. Vegetative propagation of Endospermum malaccense by leafy stem cuttings: effects of indole butyric acid (IBA) concentrations and propagation systems (mist and non mist). Journal of Tropical Forest Science, v.15, p.249$258,2003$.

BANERJEE, M.; AGARWAL, B. In vitro rooting of tea (Camellia sinensis L.) O. Kuntze). Indian Journal of Experimental Biology, v.28, p.936-939, 1990.

BASTOS, D.C. et al. Estiolamento, incisão na base da estaca e uso de ácido indolbutírico na propagação da caramboleira por estacas lenhosas. Ciência e Agrotecnologia, v.33, n.1, p.313-318, 2009. Disponível em: <http://www.scielo.br/scielo.php?script=sci_arttext\&pid=S1413$70542009000100043 \& \operatorname{lng}=$ en\&nrm=iso\&tlng=pt $>$. Acesso em: 29 set. 2010. doi: 10.1590/S1413-70542009000100043.

DAVIS, T.D. Photosynthesis during adventitious rooting. In: DAVIS, T.D. et al. (Eds.). Adventitious root formation in cuttings. Portland: Dioscorides, 1988. Cap.16, p.214-234.

GRANGE, R.I., LOACH, K. The water economy of unrooted leafy cuttings. Journal of Horticultural Science, v.58, n.1, p.9-17, 1983.

JHA, T.; SEN S.K. Micropropagation of an elite Darjeeling tea clone. Plant Cell Report, v.11, n.2, p.101-104, 1992. Disponível em: <http://www.springerlink.com/content/ b52b6b6eb7f5d19c/fulltext.pdf>. Acesso em: 15 jun. 2010. doi: 10.1007/BF00235263.

KHAN, N.; MUKHTAR, H. Tea polyphenols for health promotion. Life Sciences, v.81, n.7, p.519-533, 2007. Disponível em: <http://www.sciencedirect.com/ science?_ob=MImg\&_imagekey=B6T 99-4P2S 983-9-

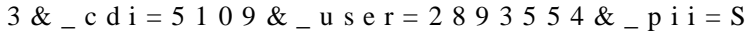
$0024320507004717 \&$ \&origin=search\&_cover Date $=07 \% 2 F 26 \% 2 F 2007 \& \_s k=999189992 \& v i e w=c \& w c h p=d G L z V z b-$ $\mathrm{zSkWb} \& \mathrm{md} 5=136856 \mathrm{c} 1 \mathrm{c} 9 \mathrm{f} 0 \mathrm{a} 28215 \mathrm{bfc} 3628 \mathrm{cad} 46 \mathrm{e} 7 \& \mathrm{ie}=/$ sdarticle.pdf >. Acesso em: 20 mar. 2010. doi: 10.1016/ j.lfs.2007.06.011.

KIBBLER, H. et al. Adventitious root formation in cuttings of Backhousia citriodora F. Muell. 1. Plant genotype, juvenility and characteristics of cuttings. Scientia Horticulturae, v.102, n.1, p.133-143, 2004. Disponível em: <http://www.sciencedirect.com/ science?_ob=MImg\&_imagekey=B6TC3-4BWYDYN$28 \&$ \& c di $=5159 \&_{\text {_u ser }}=2893554 \&_{\text {_p pi i }=S 0304}$ $423804000329 \&_{\text {_origin }}$ orearch \& _ cover D ate $=10 \% 2 \mathrm{~F} 15 \% 2 \mathrm{~F} 2004 \& \_\mathrm{sk}=998979998 \& \mathrm{view}=\mathrm{c} \& \mathrm{wchp}=\mathrm{dGLzVlz}-$ zSkzk\&md5=94f8873edfc206651573f458ea 1 bda20\&ie $=/$ sdarticle.pdf $>$ Acesso em: 15 jun. 2010. doi:10.1016/ j.scienta.2003.12.012.
LIMA, J.D. et al. Chá: aspectos relacionados à qualidade e perspectivas. Ciência Rural, v.39, n.4, p.1270-1278, 2009. Disponível em: <http://www.scielo.br/pdf/cr/v39n4/a132cr546.pdf>. Acesso em: 14 set. 2010. doi: 10.1590/S0103-84782009005000026.

OHLAND, T. et al. Enraizamento de estacas apicais lenhosas de figueira 'Roxo de Valinhos' com aplicação de AIB e cianamida hidrogenada. Revista Brasileira de Fruticultura, v.31, n.1, p.273-279, 2009. Disponível em: <http://www.scielo.br/ scielo.php?pid=S0100-29452009000100039\&script=sci_arttext $>$. Acesso em: 29 set. 2010. doi: 10.1590/S0100-29452009000100039.

ROUT, G.R. Effect of auxins on adventitious root development from single node cuttings of Camellia sinensis (L.) Kuntze and associated biochemical changes. Plant Growth Regulation, v.48, n.2, p.11-117, 2006. Disponível em: <http:// www.springerlink.com/content/p0110112u2717t31/>. Acesso em: 14 jun. 2010. doi: 10.1007/s10725-005-5665-1.

SARANGA, J.; CAMERON, R. Adventitious root formation in Anacardium occidentale $\mathrm{L}$. in response to phytohormones and removal of roots. Scientia Horticulturae, v.111, n.2, p.164172, 2007. Disponível em: <http://linkinghub.elsevier.com/ retrieve/pii/S0304423806004183>. Acesso em: 14 jun. 2010. doi: $10.1016 /$ j.scienta.2003.12.012.

SENEVIRATNE, P. et al. Studies on the tissue culture of tea (Camellia sinensis (L.) O. Kuntze) 2. Rooting of shoots produced in culture. Sri Lankan Journal Tea Science, v.57, n.1, p.16-19, 1988.

SHARMA, M. et al. Direct rooting and hardening of tea microshoots in the field. Plant Cell, Tissue and Organ Culture, v.58, n.2, p.111-118, 1999. Disponível em: <http:/ /www.springerlink.com/content/r1876j8521tn7446/ fulltext.pdf $>$. Acesso em: 14 jun. 2010. doi: 10.1023/ A: 1006374526540 .

YONGHONG, Y. et al. Changes in growth regulator levels during rooting of tea cuttings. Journal of Southwest Agricultural University, v.27, n.6, p.795-798, 2005.

YUERONG, L. et al. Anatomic and biochemical studies during rooting in tea cutting. Journal of Tea Science, v.1, n.2 p.48$53,1985$.

ZHONGXU, S. et al. Research on technology of cutting propagation of tea tree in Shandong province. Journal of Shandong Agricultural University, v.32, n.3, p.285-288, 2001.

ZEE, F. et al. Small-scale tea growing and processing in Hawaii. New Plants for Hawaii, CTAHR, 2003. NPH-9. 14p. 